\title{
Histamine antagonists to temper the cytokine overproduction in gastrointestinal cells infected by SARS-CoV-2
}

\author{
A data / text minig study guided by biochemical knowledge
}

Han Geurdes ${ }^{1}$ and Ivoyl Koutsaroff ${ }^{2}$

\begin{abstract}
The premise regarding COVID-19 disease is that it is a spectrum which begins with infection with viral SARS-CoV-2 exposure via airborne or oral virus particles. The individual response to it depends on many factors including co-morbid conditions. An important aspect of SARS-CoV-2 virus infection is the cytokine storm that develops after the infection. The immuno-chemical chaos created in this cytokine storm is to the benefit of the virus. In this meta analysis the authors explore ways to let the cytokine storm die down by looking into the role of histamine. Histamine is a metabolic product of the essential aminoacid histidine. Histamine has 4 known receptors: H1, H2, H3 and $\mathrm{H} 4$.

The immunoglobulines IgE and IgM are indicative for a COVID-19 infection. This immune response is related to inflammation. Inflammation, in turn, runs mainly via histamine after e.g. virus inoculation. The goal of the meta-study is to gather evidence to primarily block the $\mathrm{H} 4$ receptor (H4R) in gastrointestinal cells to diminish the cytokine overproduction in the $\approx 30 \%$ of the patients suffering from gastrointestinal problems caused by SARS-CoV-2.

Our concept is as follows. If we can strike a careful balance between hampering the gastrointestinal spreading of the virus and histamine antagonists to tackle the cytokine storm, then the natural immunity can later on come on line again and attack the virus without being led astray by cytokine chaos. We will concentrate on H4R but also look at H1R and H2R related effects. The proposed substances in our systemic approach can be balanced for an effective early treatment. The nature of our work is by its method and results theoretical. In that respect we also may note the structural chemistry indol skeleton resemblance among a number of different drugs.
\end{abstract}

\section{Highlight}

With our approach we found e.g. JNJ-7777120 being capable to suppress cytokine overproduction via histamine. With indomethacine we are likely able to hamper the nonstructural protein nsp7 route of infection. In the gastrointestinal cells, the H4R antagonist JNJ7777120 repairs the damage done by indomethacine.

Keywords: Cytokine storm; IL-1 and IL-6 production via SARS-CoV-2; gastrointestinal H4R receptor antagonists

Addresses:

1 Independent data analyst / Chemical engineer GDS Appl Math BV, C. vd Lijnstraat 164 2593, NN Den Haag,

Netherlands han.geurdes@gmail.com

Technical Advisor, ACS member, Mishimaoka 2-30-4-209, Ibaraki Osaka, Prefecture 567-0021,

Japan, ikoutsar@earthlink.net

The authors wish to thank A. Popper, MSc, B.T. vd Bos, BSc 


\section{${ }_{42} \quad 1$ Introduction}

43 The illness COVID-19 is caused by the virus SARS-CoV-2. SARS-Cov-2 is a single-stranded

44 RNA virus. Viruses are very tiny infectious agents that don't have metabolism or can

45 replicate exclusively on their own. Following infection of a host (e.g., a cell), a virus can direct the cell machinery to produce viral proteins and produce more viruses. SARS-Cov-2

is, not only in name, closely related to a bat coronavirus SARS-CoV [F. Wu et. al. (2020)].

48 The spike S structure of SARS-Cov-2, i.e. the machinery with which the virus injects its RNA into the host, shows resemblance to RaTG13 bat virus [C. Zhang et. al. (2020)]. There has been significant discussion about the origin of the SARS-CoV-2 for example see [K.G. Andersen (2020)]. SARS-CoV-2 and SARS-CoV likely do differ in drug sensitivity profile [D. Bojkova et. al. (doi 024257)].

In this paper we will focus on a treatment with antihistamines to let the cytokine overproduction, i.e. the storm [A. George(2020)], die down. It is remarkable that a systemic antihistamine route with supporting substances to fight the physiological consequences of the virus appears to be largely ignored in the treatment of COVID-19.

We believe that a systemic approach can exist next to direct attack approaches such as the use of antiparasitic ivermectine [L. Caly et. al. (2020)] and [S. Omura and A. Crump (2004)], to eliminate the virus. In a previous study in Parasitology, [M. S. Sajid et. al. (2006)], it was reported that pro-inflammatory interleukin IL-1 $\beta$ was most likely increased in human material tested in vitro after treatment with ivermectin. The interleukines IL-1 and IL-6 are the cytokines that are generated via the virus to create cytokine chaos and to sneak through the immunity defenses. Moreover, IL-6 induces the overexpression of ACE2 receptors [S. Wassermann et. al. (2004)] on the host cell. So the ACE2 route of infection can be furthered by interleukin production. Histamine can influence the production of IL-1 in the lung tissue [J. Sirois et. al. (2000)]. The mechanism of action of ivermectin is its resemblance to gamma-amino butiric acid (GABA) [N.E. Scott(2008)]. Additionally, there can be clinical toxicity problems associated with ivermectine, like e.g. ataxia and bradycardia [N.E. Scott(2008)]. It is used in HIV-1 treatment and can, therefore, count as support substance to histamine in the attempt let the cytokine storm die down. The latter is the first pillar in our system theoretical treatment approach.

\section{Inflammation}

73 A major aspect of the SARS-CoV-2 infection is the occurrence of inflammation. An inflammatory response is the coordinated activation of signaling pathways that regulate inflammatory mediator levels in resident tissue cells and inflammatory cells recruited from the blood. The inflammation reactions can depend on local cellular environmental surroundings but they all share 1) cell surface pattern receptors recognize detrimental stimuli; 2) inflammatory pathways are activated; 3) inflammatory markers are released; and 4) inflammatory cells are recruited [L. Chen et. al. (2018)].

In [M.D. Hayes et. al. (doi 78285)], inflammation of tumour growth is described that shows epithelial cell growth and differentiation partly through IgE, histamine H1 and H4 engagement. The amount of natural $\mathrm{IgE}$ and of histamine are related. $\mathrm{IgE}$ is one of the immunoglobulins that can be used to recognize viral material and finally neutralize it. One of the interleukines ( IL-33 ) strongly potentiates IgE-mediated activation [E.Rönnberg et. al. (2019)]. If $\mathrm{IgE}$ is not guided to eliminate the virus then IL-33 will be at best ineffective.

Let us recapture the importance of histamine. We mention upfront a study where histamine is coupled to the immunoregulation of HIV infected patients 
[Z.I. Akhmedjanova et. al. (2012]. During inflammation, histamine is released from preformed stores in and basophils. mast cells Histamine acts on vascular smooth muscle cells and endothelial cells, leading to vasodilation and an increase in vascular permeability [R. L. Thurmond et. al. (2008)]. Histamine has multiple effects on both the direct as well as the indirect immune response. To be more precise we recall

[M. S. Sajid et. al. (2006)]: The direct mechanism of immunomodulation involves interaction of an immunomodulator and/or its metabolite with a component of the immune cell itself. This can be investigated in vitro. The indirect mechanism of immune modulation involves interaction of the immunomodulator and/or its metabolite with a component of a non-immune cell. This depends on in vivo connections and is more difficult in vitro.

In the paper we will focus on the role of histamine outside the central nervous system. This is the reason why we not go very deep into the histamine 3 receptor $(\mathrm{H} 3 \mathrm{R})$. Obviously we are not excluding effects of antihistamines on the central nervous system microglia [P. Zhou et. al. (2019)]. Moreover, histamine H3 receptors (H3R) are also present in lung tissue and play an inhibitory role in the production of pro-inflammatory cytokine. There is increasing evidence suggesting that histamine is involved in the regulation of cytokine networks. More strongly: histamine can inhibit, next to IL-1, also inhibit the release of IL-2, IFN-g, and TNF (1115) and increase the release of IL-5, IL-6, and IL-8 [J. Sirois et. al. (2000)].

Therefore, it depends which histamine receptor one targets in suppression and in which tissue it resides. Histamine H3 receptors (H3R) are involved in gastric mucosal defense, inhibition of enteric neurotransmission and feedback regulation of histamine release

[G. Coruzzi et. al. (2012)]. A large body of evidence has unraveled the occurrence of histamine H4 receptors (H4R) in the gastrointestinal tract [G. Coruzzi et. al. (2012)].

\section{$2.1 \quad H 1 R$}

Concerning the role of the histamine $\mathrm{H} 1$ receptors (H1R) let us look e.g. at levocetirizine. This substance blocks the histamine H1R. In [M. Staevska(2009)] it is demonstrated that levocetirizine helps to fight difficult urticaria. It is in that respect interesting to mention the fact that this substance inhibits the cytokine expression and viral replication of rhino virus [Y.J. Jang et. al. (2009)]. Closely related to the rhino infection we may note that levocetirizine inhibits Inter Leukine 6 (IL-6) which also occurs in SARS-CoV-2 infection. The SARS-Cov-2 virus furthers the synthesis of IL-6 and along a.o. this route makes a cytokine storm. Note: The pathophysiology of SARS-CoV-2 is complex and largely unknown but is associated with an extensive immune reaction triggered by the excessive production of interleukin 1 beta (IL-1 $\beta$ ), interleukin 6 (IL-6) and others [N. Kumar et. al. (2020)]. Both cetirizine (a metabolite of hydroxyzine ) and levocetirizine are $\mathrm{H} 1$ receptor antagonists. Levocitirizine (pubchem/compound/1549000) and citirizine (pubchem/compound/2678) are stereochemically related. In [M.C. Jung et. al. (2016)] we can read that levocetirizine can imply iatrogenic complications. We surmise that this, because of similarities between the two molecules, most likely is also true for citirizine.

\subsection{H2R, the usnic acid / usneate case}

Usno or benzyldimethyl-(2-[2-(p-1,1,3,3-tetramethylbutylphenoxy)ethoxy] ethyl)ammonium usneate, is a substance that can be found in lichens. We refer to pubchem/compound/5646. In already older studies it was found to have a biological action [S. Huneck(1968), pp. 306-308]. In this latter study molecular information is readily available. Considering the biochemistry, M. Cocchietto, points at the fact that Usno is inhibitory against leukotriene biosynthesis [M. Cocchietto et. al. (2002)]. Leukotienes and histamine are physiologocally 
related. The relationship is also expressed in the response of the $\mathrm{H} 2$ receptor behavior. The production of leukotrienes is most of the time accompanied by the production of histamine and prostaglandines [J.A. Salmon and G.A. Higgs (2007)].

Leukotrienes are a family of lipid inflammatory mediators produced in leukocytes (white blood cells). They are the metabolic oxygenation of arachidonic acid by the enzyme 5lipoxygenase (5-LO). For an overview of the biosynthesis of leukotrienes viz. [A. Jo-Watanabe et. al. (2019), fig. 1]. Leukotrienes use lipid signaling to perform a regulation of immune response. Interestingly enough it was reported in [N. Flamand et. al. (2004)] that the cellular signal substance cAMP, suppresses 5-OL. The leukotrienes exert their biological effects by binding to $\mathrm{G}$ - protein - coupled receptors (GPCRs) [A. Jo-Watanabe et. al. (2019)]. The histamine receptors, including H4R, are G - protein based. E.g. the particular leukotriene $\mathrm{LTB}_{4}$ is a strong attractant for many immune cells.

By the cAMP suppressive action for the synthesis of leukotrienes, it looks as though cAMP might take priority in cellular signaling. Furthermore, H2R activation runs most likely via stimulating cAMP synthesis. Referring back to the co-synthesis of histamine and leukotrienes and with an eye on the role of cAMP and leukotrienes under infection, we may note [N. Flamand et. al. (2004)] that histamine suppresses the biosynthesis of leukotrienes. This is what both cAMP, histamine and Usno have in common. Human polymorphonuclear leukocytes (PMN) carry $\mathrm{H} 2$ receptors and are activated by the leukotriene $\mathrm{LTB}_{4}$. $\mathrm{H} 2$ receptor antagonists like cimetidine abrogate the suppression of leukotriene biosynthesis. The inhibition of LT biosynthesis by histamine was characterized by decreased arachidonic acid release and 5-lipoxygenase translocation to the nuclear membrane [N. Flamand et. al. (2004)]. An $\mathrm{H} 4$ receptor blocker like e.g. thioperamide does not influence the biosynthesis of leukotrienes. This is in slight contrast to the fact that leukotrienes bind to G-protein receptors and H4R is of G-protein type.

Despite this unclarity it could be worthwhile to employ $\mathrm{H} 4$ blockers without affecting the synthesis of leukotrienes on the human PMN. Should one want to slightly block the leukotrienes biosynthesis then e.g. Usno can be employed [M. Cocchietto et. al. (2002)]. Usno is toxic however (pubchem/compound5646) and therefore might show iatrogenic difficulties. Nevertheless the stereo-chemical similarity to a 2,5-dihydroxyquinone "nucleus" in polyporic acid is most likely the active center [S. Huneck (1968), pp. 307]. This is perhaps a good starting point for altering the molecule to a less toxic level. The mechanisms of the antibiotic activity of usnic acid (viz. Usno) against Gram-positive bacteria were attributed to its role as an uncoupler of oxidative phosphorylation, inhibiting the synthesis of adenosine triphosphate [M. Kosanić and B. Ranković (2019), pp. 101]. The same review reveals that usnic acid delivers apoptosis through the enabling of more protonated molecules to cross the membrane and release protons into the cell. As a result, the intracellular $\mathrm{pH}$ decreases and lead to the death (apoptosis) of the cells. This would in particular be interesting for therapies like with $Z n$ where there is the suspicion that viral particles survive in infected cells.

\section{$2.3 \quad \mathrm{H} 4 \mathrm{R}$}

$\mathrm{H} 4 \mathrm{R}$ is the newest of the four known histamine receptors. It belongs to the group of $\mathrm{G}$ - proteins and is coupled to the $G_{i \backslash o}$ protein [Y. Ikawa et. al. (2008)]. H4Rs have been detected in different cell types of the gut, including immune cells, paracrine cells, endocrine cells and neurons. Moreover, H4R expression was reported in human colorectal cancer specimens [G. Coruzzi et. al. (2012)]. A systematic list of H4R contains cells like mast cells, eosinophils, leukocytes, monocytes, CD8+T cells, basophils, dendritic cells, spleen and bone marrow [C.M. Marson (2011)]. The H4 receptor is expressed throughout the gastrointestinal tract as well as in the liver, pancreas and bile ducts [A. Deiteren et. al. (2014)]. H4Rs to 
modulate the function of mast cells, T cells, dendritic cells and eosinophils, it is natural to foresee a therapeutic potential of H4R antagonists in inflammatory disorders of the GI tract [G. Coruzzi et. al. (2012)].

Eosinophils are stimulated by histamine and so the $\mathrm{H} 4$ receptor $(\mathrm{H} 4 \mathrm{R})$ plays an interfering role in generating the eosinophils that can attack intruding agents. In gastrointestinal SARSCoV-2 infection [F. Xiao et. al. (2020)], we can look at the H4 receptor as one of the sources of the cytokine storm. The hypothesis is: to block the $H_{4} R$ in gastrointestinal cells and let the cytokine overproduction, i.e. cytokine storm dies down.

In this respect we note the following. There are mast cells that can fire the cytokine storm via interleukine, [E.Rönnberg et. al. (2019)]. The latter study was performed with interleukine 33 (IL-33). We note that SARS-CoV-2 furthers the production of interleukine 6 (IL-6) and this also is able to fire and is in fact part of, the cytokine storm. This route of generating the storm is operative without the interference of $\mathrm{H} 4$ receptor in gastrointestinal infected epithelial cells. In a medical treatment with an $\mathrm{H} 4 \mathrm{R}$ blocker it represents a shunt and is a logical sense bypass to the blocking. It is an interesting question how much the mast cells that employ the interleukine H4R blocking shunt fires the cytokine storm.

An interesting case of an $\mathrm{H} 4$ receptor influence is the case of indomethacin. Functional characteristics of the $\mathrm{H} 4 \mathrm{R}$ in fibroblasts are associated with inflammatory disorder. This is related to e.g. dermal dexametasone [E. Zampelli and E.Tiligada (2009), table 1]. Apparently indomethacin can also have a direct anti-inflammatory effect by inhibiting the synthesis of prostaglandins, the signaling molecules. Further, H4R expression occurs in numerous immune and inflammatory reactions and in e.g. gastric acid secretion [Y. Ikawa et. al. (2008)]. Indomethacin is presently under study for fighting COVID-19 [D.E. Gordon, et. al.(2020), entry PTGES2, table 1a]. Concerning toxicity, it is most likely that indomethacin is expected to have a low iatrogenic impact [B.Polat et. al. (2010)] The target protein in SARS-CoV-2 is one of the nonspecific proteins, nsp7. The nsp7 is a cofactor in the expression of the viral RNA [Y.Gao et. al. (2020)]. The occurrence of an anti-inflammatory agent in the larger study, supports our quest for studying the role of $\mathrm{H} 4$ blocking treatment that bcan be experimentally researched further.

5-chloro-2-[(4-methylpiperazin-1-yl)carbonyl]-1H-indole (JNJ-7777120) is a specific H4R antagonist. An experimental study of Ballerini [C. Ballerini et. al. (2013)] suggest that autoimmune diseases are furthered by JNJ-7777120 H4R antagonist and furthered an increase of inflammation. There might be iatrogenic problems in the use of JNJ-777120. Another appropriate not too toxic H4R antagonist is JNJ-10191584 (VUF 6002) [M. Zhang et. al. (2006)].

\subsection{Supportive substances and/or synthetic derivatives.}

Usno \& target leukotrienes Usnic acid is a secondary metabolite of lichen $[M$. Kosanić and B. Ranković (2019)]. Usno is also a substance obtained from lichen. Leukotrienes synthesis can perhaps also be a target of therapeutic intervention with e.g. Usno. General references to leukotriene targets are to be found in [J.N. Sharma and L.A. Mohammed(2006)] and [A. Jo-Watanabe et. al. (2019)]. Direct anti-viral activity to the influenza virus is also present in both (+) and (-) Unso / usnic acid [D.N. Sokolov et. al. (2012)]. Evidence for anti-viral effect where usnic acid is a repressor of RNA transcription was given early 2000, see: [A. A. S. Araujo et. al. (2015)]. This aspect next to the anti-inflammatory activity, could make usnic acid a proper supportive substance for diminishing the cytokine storm with histamine response suppression. There is the already mentioned connection between Usno and H2R.

Atranorin \& protolichesterenic acid Another lichen substance, atranorin, is effective against hepatitis C (HC) virus [T. H. Vu et. al. (2015)]. In this study, the aldehyde group 
of atranorin was demonstrated to hamper the entry of the $\mathrm{HC}$ virus into the host. It is worth while to investigate if atranorin is a direct antiviral to SARS-CoV-2. A related matter is the possible blocking of HIV reverse transcription [M. Phillips and J. Svärd, (2015), pp.57]. If a similar mechanism of reverse transcription is employed in SARS-CoV-2, then the lichen derived protolichesterenic acid is a not toxic frustration for the virus to create nascent DNA from its RNA. This hampers the spreading infection of the virus. In this respect, the authors wonder why the paper [P. Pradhan et. al. (2020)] was retracted that suggested HIV elements in SARS-CoV-2. If that is true then perhaps a similar mechanism of infection as in HIV is employed by SARS-CoV-2. Using protolichesterenic acid can be a supportive substance for the blocking of the histamine fired cytokine storm. The opposite paper [C. Zhang et. al. (2020)] that questions the conclusions of [P. Pradhan et. al. (2020)] is referred to as well. From the latter we read that the HIV elements are short sections that are not unique to SARS-CoV-2 and HIV. It must be noted that the presence of gp120 on the $\mathrm{S}$ spike protein of SARS-CoV-2 is not denied by Zhang cum suis. Therefore looking at how HIV infects, [M. Phillips and J. Svärd, (2015), pp. 4], we may still hold that SARSCoV-2 behaves in some ways similar, cit: "At the initial stage, HIV comes into contact with a CD4-expressing cell (such as a helper T cell or macrophage). The main glycoprotein needed for this interaction is gp120 on the virion surface, which forms a trimer together with a transmembrane component, gp41". If people call the [P. Pradhan et. al. (2020)] study shoddy then to our minds the $[C$. Zhang et. al. (2020)] study is perhaps credited too much. It is also noted that the rejection of HIV elements on the spike S protein of SARS-CoV-2 obviously does not refute the possibility of SARS-CoV-2 using reverse transcription in the process of replication.

Indomethacin This substance interferes with one of the nonspecific proteins involved in the SARS-CoV-2 transcriptase complex. Moreover, indomethacin [C. Amici et. al. (2006)] has a potent antiviral effect against the SARS-CoV virus from begin 2000. Indomethacin targets the nsp7 protein of the SARS-Cov-2 virus and is a prostaglandin E2 synthase inhibitor [D.E. Gordon, et. al.(2020)].

HIV gp120 blocker Recently Pradhan et al claimed that there are HIV elements in the S spike protein of the SARS-CoV-2 virus [P. Pradhan et. al. (2020)]. In a paper by Zhang [C. Zhang et. al. (2020)] it was contested that such "inserts" were proof of an engineered virus. If we leave that discussion for what it is, then, we note that [C. Zhang et. al. (2020)] does not deny that gp120 is present on the S spike of the virus. [M. Phillips and J. Svärd, (2015)] informs us that gp120 is the main protein needed by the virus to make contact with CD4+ type of cells (helper $\mathrm{T}$ cells and macrophage cells). The protein gp120 forms a trimer with the transmembrane gp41 and in this way a virus carrying gp120 can insert its RNA into the host $[M$. Phillips and J. Svärd, (2015), figs. 1 \& 2, pp. 5]. Because SARS-CoV-2 carries this structure it is likely that it is used in the infection. We explicitly note that [C. Zhang et. al. (2020)] did not demonstrate that the gp120 segments on the S spike are not active. Therefore CD4+ binding disturbing substance like maraviroc may hamper the SARS-CoV-2 virus propagation / multiplication [M. Phillips and J. Svärd, (2015), pp. 5]. Interestingly, concerning CD4+ cells we may observe the role of fenbendazole. Fenbendazole is a member of benzimidazole group of anthelminthics like ivermectin (pubchem/compound 6321424). In [M. S. Sajid et. al. (2006)] we read that the administration of fenbendazole to healthy mice stimulated the proliferative response of T- and B-cells to non-specific polyclonal activators, but partially inhibited the CD4+, CD8 percentage of and +T-lymphocytes. If gp120 in the S spike of SARS-CoV-2 actually targets CD4+, then fenbendazole might hamper the CD4+ infection route. The treatment of nematode infected mice considerably stimulated the proliferative response of B-cells in comparison with T-cells. 
Zinc Zinc possesses direct antiviral properties, e.g. against influenza. Zinc is captured in vivo in metallothioneins and it should be noted that metallothioneins, although highly responsive to zinc, have long been classified as interferon (IFN) stimulated genes. IFNs are immunostimulatory cytokines secreted from infected cells and nearby immune cells that induce the expression of hundreds of antiviral genes [S.A. Read et. al. (2019)]. Zn avoids the apoptosis of cells that contain virus material. Some metallothioneins [S.A. Read et. al. (2019)] are generated by some viruses as a response to Zn. Not all metallothioneins fire IFN or prevent apoptosis of infected cells but the authors wonder if $\mathrm{Zn}$ is not too complicated where we are trying to let a cytokine storm die down.

ACE2 receptor antagonism The, on the host cell residing, angiotensin converting enzyme 2 is recognized as one of the receptors of the S spike of SARS-Cov-2 RNA infection of the host. Generally angiotensin converting enzyme is related to blood pressure regulation [A. Michaud et. al. (1997)]. ACE2 is accountable for human-human infection [Y. Wan et. al. (2020)]. In Gordon's research of $\approx 300$ protein interactions, captopril [D.E. Gordon, et. al.(2020)] is considered a modulator / competitive inhibitor of the ACE2 binding. It decreases the level of angiotensin 2. A search on pubchem showed that there are other competitive inhibitors of ACE2 binding like e.g. fosinopril. Like captopril, fosinopril competitively inhibits ACE thereby it decreases the formation of the potent vasoconstrictor, angiotensin 2. The latter is one of the main factors in in hypertension induced tissue damage (pubchem/compound 172198) and [S. A. S. Farhadi and K. F. Dizaye (2019)]. Diminishing the angiotensin 2 production with suppresing its production implicitly also lowers the cytokine production and the synthesis of new ACE2 receptors

[S. Wassmann and G. Nickenig (2006)].

\section{Conclusion \& discussion}

Histamine has a direct modulating effect.

In our theoretical paper we focused on histamine 1,2 and 4 receptor types. Although histamine 3 receptor also occurs in lung tissue and neuro-endocrine gastrointestinal tissue, we have not inspected it very deeply. H3 receptors are more associated to neuro or neuro endocrine tissue. This will most likely warrant a subsequent study.

Looking at a possible gp120 to CD4+ infection route of SARS-C0V-2, the lowering of histamine is immediately hampering CD4+ activity. Perhaps it is too simple to say in vivo; less histamine less CD4+ and therefore less gp120-CD4+ infection. However, the direct influence already shows the importance of antihistamines in hampering SARS-CoV-2.

In the analogous virus, SARS-CoV, the RNA genome replication is a crucial step in SARS-CoV propagation and is mediated by the RNA replicase [D. G. Ahn et. al. (2014)]. The S spike of SARS-CoV-2 also contains the replicase necessary cofactor nsp7. So it makes sense to believe that the virus propagation can run similar to SARS-CoV. From the study done by [C. Zhang et. al. (2020), fig. 1] we may observe that SARS-CoV does not contain the HIV elements such as SARS-CoV-2. It therefore makes sense to hypothesize that SARSCoV-2 also has ways to propagate that differ from SARS-CoV. Nevertheless, interference with indomethacin therewith targeting cofactor nsp7 is a genuine possibility to hamper SARS-CoV-2 virus propagation.

The role of histamine in the generation of interleukins IL- 1 and IL- 6 that also may further the possibility of infection via ACE2 is another more indirect effect of histamine and provides reason to look at the possibility of antihistamines next to competitive inhibitors of ACE2. Competitive antiangiotensins also may suppress the creation of ACE2 receptors on the host cell. 
We note here that indomethacin (pubchem/compound 3715) shares a 2D structural indol resemblance with serotonin (pubchem/compound 160436). In this case we are looking at the indol skeleton and the $\mathrm{OH}$ substitute at the same 2D indol structure. Interestingly enough in HIV-1 we have LEDGF/p75 integrase inhibitors; a strong binding partner of HIV-1 integrase [M. Phillips and J. Svärd, (2015), pp. 23]. There are a group of rationally designed small molecules containing the indol skeleton [V. Hann and M. Ashton (2015)] that targets the LEDGF/p75-IN. All of those molecules, like e.g. CHIBA-3000, have an indole skeleton [V. Hann and M. Ashton (2015), pp. 232, fig. 27]. In the indol (Fig. 1) the $\mathrm{OH}$ group resides at another position relative the $\mathrm{N}$ than serotonin and indomethacin. Perhaps that the indol (Fig. 1) sharing also points to the use of the CHIBAn molecules in SARS-CoV-2 originally targeted for LEDGF/p75-IN (integrase) in HIV-1. LEDGF/p75 is by far the most extensively studied co-factor in HIV study. It is a $74 \mathrm{kD}$ protein ubiquitously expressed, chromatin associated protein in HIV-1 infection. Because certain HIV elements are on the S spike of SARS-CoV-2, it could pay to look at substances that hamper the gp120 binding of the virus to $\mathrm{CD} 4+$ cells. It is noted here that the N-terminal domain structure (aminoacids 1-49) of the HIV-1 IN protein resemble the zinc finger [S.A. Read et. al. (2019)] with a His, Cys, Cys combination [M. Phillips and J. Svärd, (2015), pp.189]. The S of cystine provide the binding place for e.g. $\mathrm{Mg}^{2+}$ or $\mathrm{Zn}^{2+}$, There is a connection with the LEDGF approach to hamper the integrase in which in HIV-1 the IN protein participates. With this way of looking at an alternative binding via the gp120 on the S spike (confirmed by [C. Zhang et. al. (2020)]) we are obviously not forgetting the ACE2 binding but merely mention other possible ways of infection. Before entering more deeply into the possibilities of antihistamines, we note that there already existed in the literature, objections against what is called the non-steroidal anti-inflammatory drugs (NSAIDs). No conclusive evidence against their use could be concluded howerver [B. Russell1 et. al. (2020)].

The more general aim of the study was:

- (1) Find means to let the cytokine storm for at least gastrointestinal infection die down

- (2) To provide supportive substances that hamper the virus replication.

- (3) Use e.g. IgE 'trained' to attack the virus when the attack is most effective. To our minds it is most effective after the cytokine chaos is resolved or a situation is created where the chaos cannot arise.

We studied possible routes. E.g. it is possible to (1) suppress H4R in gastrointestinal cells with JNJ-7777120, to use (2) maraviroc to hamper infection via gp120 and use (3) $\mathrm{IgE}$ trained cells to eradicate the SARS-CoV-2 virus. In table- 1 we present a number of combinations that may look interesting for further experimental research. Another route is to replace (2) with indomethacin and keep (3) as it is. Obviously JNJ-7777120 can be replaced with thioperamide. Therefore we can obtain a combinatorial matrix of possibilities (table-1). It is noted that substances like atranorin and usnic acid can also play a role in (2). Concerning the supportive substances we mention the following. Lichen substances show weak antiviral activity. Furthermore, the role of Zn is somewhat confusing. Especially the role of metallotrienes needs to be sorted out further. (1) lowers or prevent the cytokine storm with H4R antagonists, (2) hampers the virus multiplication and (3) eliminates the virus. If necessary, (1) can be supplemented with cetirizine or levocetirizine to block the H1R and we may also look at leukotrienes. (2) can be supplemented with atranorin to hamper other aspects of virus multiplication. Most likely there are also other ways to obtain (3).

Concerning (3) we acknowledge that this aspect is not studied very deeply either. The role of $\operatorname{IgE}$, IgM and IgA might also necessitate a follow up if it is possible. 
Interestingly, Adami [M. Adami and G. Coruzzi (2014)] found that the H4R antagonist JNJ-7777120 is able to undo the gastric damage of indomethacin. The "ok" in the tox column of table-1 is based on their finding. Perhaps that a similar siuation is valid for JNJ-10191584. It is hence possible to block the cytokine storm, hamper the nsp7 guided infection and undo the damage of indomethacin. Contrary to JNJ-7777120, the H4R antagonist thioperamide does not have an indol (Fig.1) skeleton. Moreover, there are two N atoms in the five ring and this ring is not connected to a benzene structure. Thioperamide allow LTB4 and there is most likely a larger role for the H4 receptor in LTB4 production [K. Takeshita et. al. (2003)]. It must be noted that we did our theoretical study in the field of applying non-steroidal anti-inflammatory drugs. Although there are sceptical reactions towards this approach we believe that it is a valid one in early treatment to prevent the cytokine overproduction. There is literature to support this [P. Ioannou (2020)].

We end this discussion section by noting that to our minds the structural 2D resemblance with an indol (Fig. 1) skeleton between some of the antiviral substances for SARS-CoV-2 and HIV-1, explored in this paper on the one hand and serotonin on the other cannot be altogether accidental. Especially because nsp7 is a cofactor in the polymerase of the enzyme. The chemical similarity between the indol skeleton of indomethacin and the indol skeleton of CHIBA-3000 can be an indication of a similar way of stages of the SARS-CoV-2 virus propagation and the HIV virus. Perhaps this allows us to gain insight into possible other ways of infection besides the ACE2 route. Of course quantum chemical electron cloud density studies, e.g. [Han Geurdes (1987)], or e.g. hydrogen bonding in DNA base pairs [L. Rodriguez et. al. (2010)] can provide more insight into the idea of indol skeleton similarity.<smiles>c1ccc2[nH]ccc2c1</smiles>

Fig 1. Basic Indol structure. 
Table 1: Some H4 antagonists with supportive substances and remarks made on 2D structural chemistry and a column, deisgnated tox, which is only indicative for what the authors know about the combination of those substances. ok is explained in the text, ? is we don't know.

\begin{tabular}{|c|c|c|c|}
\hline $\begin{array}{l}\text { H4R substance } \\
\text { (1) }\end{array}$ & $\begin{array}{c}\text { supportive substance } \\
(2)\end{array}$ & remarks & tox \\
\hline JNJ-7777120 & indomethacin & $\begin{array}{l}\text { blocks c-storm \& hampers nsp7 infection. } \\
\text { indol shared structure }\end{array}$ & ok \\
\hline JNJ-10191584 & indomethacin & $\begin{array}{l}\text { blocks c-storm \& hampers nsp7 infection. } \\
\text { no indol shared structure }\end{array}$ & $?$ \\
\hline Thioperamide & indomethacin & $\begin{array}{l}\text { blocks c-storm \& hampers nsp7 infection. } \\
\text { double N } 5 \text { ring twisted but } \\
\text { related to JNJ-10191584 }\end{array}$ & $?$ \\
\hline $\begin{array}{l}\text { JNJ-7777120 } \\
\text { JNJ-10191584 } \\
\text { Thioperamide }\end{array}$ & atranorin & $\begin{array}{l}\text { c-storm blocking \& hampers infection. } \\
\text { aldehyde group demonstrated to hamper } \\
\text { the entry of the Hepatic C virus. } \\
\text { no } 2 \text { D structural relatedness (1) \& (2). } \\
\text { atranorin furthers apoptosis. }\end{array}$ & $?$ \\
\hline JNJ-7777120 & CHIBA-3000 & $\begin{array}{l}\text { blocks c-storm \& interferes with } \\
\text { integrase in HIV-1 LEDGF. } \\
\text { indol shared structure. }\end{array}$ & $?$ \\
\hline $\begin{array}{l}\text { antihistamine } \\
\text { like JNJ-7777120 }\end{array}$ & captopril & $\begin{array}{l}\text { interferes with ACE2 production } \\
\text { via cytokine IL- } 6 \text { similar as H4R antagonist } \\
\mathrm{N} \text { containing } 5 \text { ring is not indol like }\end{array}$ & $?$ \\
\hline $\begin{array}{l}\text { antihistamine } \\
\text { like JNJ-7777120 }\end{array}$ & fosinopril & $\begin{array}{l}\text { interferes with ACE } 2 \text { production } \\
\text { via cytokine IL- } 6 \text { similar as } \mathrm{H} 4 \mathrm{R} \text { antagonist } \\
\mathrm{N} \text { containing } 5 \text { ring is not indol like } \\
\text { similar to captopril }\end{array}$ & $?$ \\
\hline
\end{tabular}

\section{References}

[K.G. Andersen (2020)] The proximal origin of SARS-CoV-2 , Nature Medicine, 26, $450455,2020$.

[A. George(2020)] A. George, Cytokine storm, an overreaction of the body's immune system New Scientist, http://www.newsciemtist.com/term/cytokine-storm.

[L. Caly et. al. (2020)] L. Caly, J. D. Druce, M. G. Catton, D. A. Jans, K. M. Wagstaff, The FDA-approved drug ivermectin inhibits the replication of SARS-CoV-2 in vitro, Antiviral Research 178, 104787, 2020, doi.org/10.1016/j.antiviral.2020.104787.

[S. Omura and A. Crump (2004)] S. Omura and A. Crump, The life and times of ivermectin-a success story, Nature, tropical and infectious disease, 2, 984- 989, 2004.

[R. L. Thurmond et. al. (2008)] R. L. Thurmond, E. W. Gelfand and P. J. Dunford, The role of histamine $\mathrm{H}_{1}$ and $\mathrm{H}_{4}$ receptors in allergic inflammation: the search for new antihistamines, Nature Reviews, Drugs Discovery, 7, 41-53, 2008.

[M. S. Sajid et. al. (2006)] M. S. Sajid, Z. Iqbal, G. Muhammad and M. U. Iqbal, Immunomodulatory effect of various anti-parasitics : a review , Parasitology, 132 301-3113, 2006 doi:10.1017/S0031182005009108. 
[N.E. Scott(2008)] N.E. Scott Ivermectine toxicity, In: Small animal critical care medicine, Ed.: D. Silverstein and K. Hopper, Elsevier, pp. 392-393, 2008 veteriankey.com/ivermectin-toxicity .

[P. Zhou et. al. (2019)] P. Zhou, J. R. Homberg, Q. Fang, J. Wang, W. Li, X. Meng, J. Shen, Y Luana, P. Liao, D. F. Swaab, L. Shan and C. Liu, Histamine-4 receptor antagonist JNJ77r7120 inhibits pro-inflammatory microglia and prevents the progression of Parkinson-like pathology and behaviour in a rat model, Brain, Behavior, and Immunity, 76, 61-73, 2019.

[J. Sirois et. al. (2000)] J. Sirois, G. Ménard, A. S. Moses and E. Y. Bissonnette, Importance of Histamine in the Cytokine Network in the Lung Through H2 and H3 Receptors: Stimulation of IL-10 Production, J Immunol, 164,2964-2970, 2000.

[S. Wassermann et. al. (2004)] S. Wassmann, M. Stumpf, K. Schmidt, B. Schieffer, B. Böhm and G. Nickenig, Interleukin-6 induces oxidative stress and endothelial dysfunction by overexpression of the angiotensin 2 type 1 receptor, Circ. Res. 5, 534-541, 2004, doi::10.1161/01.RES.000115557.25127.8D.

[M. Staevska(2009)] M. Staevska, T.A. Popov, T. Kralimarkova, C. Lazarova, S. Kraeva, et al The effectiveness of levocetirizine and desloratadine in up to 4 times conventional doses in difficult to treat urticaria doi:10.1016/j.jaci.2009.11.047

[Y.J. Jang et. al. (2009)] Y.J. Jang, J.H. Wang, J.S. Kim, Levocetirizine inhibits rhinovirus-induced ICAM-1 and cytokine expression and viral replication in airway epithelial cells, Antiviral Reserach 81, 226-2233, 2009.

[M.C. Jung et. al. (2016)] M.C. Jung, J.K. Kim, J.Y. Cho, J.W. Song, B. Lee J.W. ParkJ. Sea and S.E. Kim, A case of levocitirizine-induced liver injury Clinical and Molecular hepatology, 22, 495-498, 2016.

[N. Kumar et. al. (2020)] N. Kumar, B. Mishra, A. Mehmood, M. Athar \& M. Shahid Mukhtar, Integrative Network Biology Framework Elucidates Molecular Mechanisms of SARS-CoV-2 Pathogenesis, https://doi.org/10.1101/2020.04.09.033910.

[F. Wu et. al. (2020)] F. Wu, S. Zhao, B. Yu, Y.M. Chen1, W. Wang, Z. Song, Y. Hu, Z.W. Tao, J. Tian, Y.Y. Pei1, M.L. Yuan, Y.L. Zhang, F. Dai1, et al. A new coronavirus associated with human respiratory disease in China https://doi.org/10.1038/s41586020-2008-3

[D. Bojkova et. al. (doi 024257)] D. Bojkova, J.E. McGreig, K.M. McLaughlin, S.G. Masterson, M. Widera, V. Krähling, et al, SARS-CoV-2 and SARS-CoV differ in their cell tropism and drug sensitivity profiles, biorxiv doi.org/10.1101/2020.04.03.024257.

[L. Chen et. al. (2018)] L. Chen, H. Deng1, H. Cui1, J. Fang, Z. Zuo1 J. Deng1, Y. Li1, $\mathrm{X}$. Wang and L. Zhao, Inflammatory responses and inflammation-associated diseases in organs, Oncotarget, 9, 7204-7218, 2018.

[M.D. Hayes et. al. (doi 78285)] M.D. Hayes, S. Ward, G. Crawford, R.C. Seoane, W.D.Jackson et al Natural IgE promotes epithelial hyperplasia and inflammation-driven tumour growth biorxiv, doi.org/101101/782805.

[S. Huneck(1968)] S. Huneck, Lichen Substances, In: Progress in Phytochemistry, Vol 1 Ed.: L. Reinhold and Y. Liwschitz, pp. 223-346 Interscience Publishers, John Wiley London, NY Sydney, 1968. 
[G. Coruzzi et. al. (2012)] G. Coruzzi, M. Adami and C. Pozzoli, Role of histamine H4 receptors in the gastrointestinal tract, Frontiers in Bioscience S4, 226-239, 2012

[C.M. Marson(2011)] C. M. Marson Targeting the Histamine H4 Receptor, Chemical Reviews, 111. 7121-7126, 2011, dx.doi.org/10.1021/cr900166w.

[A. Deiteren et. al. (2014)] A. Deiteren, J. G. De Man, P. A. Pelckmans and B. Y. De Winter, Histamine $H_{4}$ receptors in the gastrointestinal tract, British Journal of Pharmacology, 172, 1165-1178, 2014.

[F. Xiao et. al. (2020)] F. Xiao, M. Tang, X. Zheng, Y. Liu, X. Li and H. Shan Evidence for Gastrointestinal Q3 Infection of SARS-CoV-2 Gastroenterology doi: $10.1053 /$ j.gastro.2020.02.055

[J.A. Salmon and G.A. Higgs (2007)] J.A. Salmon and G.A. Higgs, Prostaglandins and leukotrienes as inflammatory mediators , British Medical Bulletin, 43, 285-296, 2007, doi:10.1093/oxfordjournals.bmb.a072183.

[M. Cocchietto et. al. (2002)] M. Cocchietto, N. Skert, P. Nimis and G. Sava, A review on usnic acid, an interesting natural compound, Naturwissenschaften, 89, 137-146, 2002.

[M. Kosanić and B. Ranković(2019)] M. Kosanić and B. Ranković Lichen Secondary Metabolites as Potential Antibiotic Agents, In: Lichen Secondary Metabolites, Bioactive Properties and Pharmaceutical Potential, Ed: B. Ranković, pp. 99-128, Springer, 2019 10.1007/978-3-030-16814-8.

[P. Pradhan et. al. (2020)] P. Pradhan, A. K. Pandey, A. Mishra, P. Gupta, P. K. Tripathi, M. B. Menon, J. Gomes, P. Vivekanandan and B. Kundu, Uncanny similarity of unique inserts in the 2019-nCoV spike protein to HIV-1 gp120 and Gag biorxiv, doi.org/10.1101/2020.01.30.927871.

[C. Zhang et. al. (2020)] C. Zhang, W. Zheng, X. Huang, E. W. Bell, X. Zhou, and Y. Zhang, Protein Structure and Sequence Reanalysis of 2019-nCoV Genome Refutes Snakes as Its Intermediate Host and the Unique Similarity between Its Spike Protein Insertions and HIV1, J. Proteome Research, 19, 13511360, 2020.

[N. Flamand et. al. (2004)] N. Flamand, H. Plante, S. Picard, M. Laviolette and P. Borgeat Histamine-induced inhibition of leukotriene biosynthesis in human neutrophils: involvement of the H2 receptor and $c A M P$, British Journal of Pharmacology, 141, 552$561,2004$.

[S.A. Read et. al. (2019)] S. A. Read, S. Obeid, C. Ahlenstiel, and G. Ahlenstie, The Role of Zinc in Antiviral Immunity , Adv Nutr 0, 115, 2019, doi.org/10.1093/advances/nmz013.

[J.N. Sharma and L.A. Mohammed(2006)] The role of leukotrienes in the pathophysiology of inflammatory disorders: Is there a case for revisiting leukotrienes as therapeutic targets? , InflammoPharmacology, 14, 10-16, 2006, doi.org/10.1007/s10787-006-1496-6.

[A. Jo-Watanabe et. al. (2019)] A. Jo-Watanabe, T. Okuno and T. Yokomizo, The Role of Leukotrienes as Potential Therapeutic Targets in Allergic Disorders, Int. J. Mol. Sci., 20, 3580-3601,2019, doi.org europepmc.org/article/pmc/pmc6679143.

[D.N. Sokolov et. al. (2012)] D.N. Sokolov, V.V. Zarubaev, A.A. Shtro, M.P. Polovinka, O.A. Luzina, N.I.Komarova, N.F. Salakhutdinov and O.I. Kiselev, Anti-viral activity of (-)- and (+)- usnic acids and their derivatives against influenza virus A(H1N1)2009, , Bioorganic \& Medicinal Chemistry Letters, 22, 7060-7064, 2012. 
[A. A. S. Araujo et. al. (2015)] A. A. S. Araujo, M. G. D. de Melo, T. K. Rabelo, P. S. Nunesa, S. L. Santosa, M. R. Serafinic, M. R. V. Santos, L. J. Quintans-Junior and D. P. Gelain, Review of the biological properties and toxicity of usnic acid, Natural Product Research, 2015, dx.doi.org/10.1080/14786419.2015.1007455.

[T. H. Vu et. al. (2015)] T. H. Vu, A. Le Lamer, C. Lalli, J. Boustie, M. Samson, F. LohzicLe Dvhat and J. Le Seyec, Depsides: Lichen Metabolites Active against Hepatitis C Virus , PLOS One, DOI:10.1371/journal.pone.0120405, 2015.

[E.Rönnberg et. al. (2019)] E.Rönnberg, A.Ghaib, C. Ceriol, M. Enoksson, M. Arock, J. Säfholm, et al, Divergent effects of acute and prolonged interleukin 33 exposure on mast cells IgE mediated functions Frontiers in Immunology, doi:10.3389/fimmu.2019.01361 and biorxiv doi.org/10.1101/463950.

[E. Zampelli and E.Tiligada(2009)] E. Zampeli and E. Tiligada, The role of histamine H4 receptor in immune and inflammatory disorders, British Journ of Pharmacology, 157, 24-33, 2009, doi:10.1111/j.1476-5381.2009.00151.

[M. Phillips and J. Svärd, (2015)] M. Phillips and J. Svärd, Antiretroviral Drugs: Current Therapy, Recent Developments and Future Perspectives, In: Frontiers in Clinical Drug Research: HIV (Volume 1) Ed: Atta-ur-Rahman, pp. 3- 57, Bentham Science Publ, 2015.

[V. Hann and M. Ashton (2015)] V. Hann and M. Ashton HIV Integrase Biology and Inhibitor Design, In: Frontiers in Clinical Drug Research: HIV (Volume 1) Ed: Attaur-Rahman, pp. 185-265, Bentham Science Publ, 2015.

[Y. Ikawa et. al. (2008)] Y. Ikawa, K. Shiba, E. Ohki, N. Mutoh, M. Suzuki, H. Sato and K. Ueno, Comparative study of histamine $\mathrm{H}_{4}$ receptor expression in human dermal fibroblasts, J. Toxicol. Sci., 33, 503-508, 2008.

[A. Michaud et. al. (1997)] A. Michaud, T. A. Williams, M. Chauvet, and P. Corvol, Substrate Dependence of Angiotensin I-Converting Enzyme Inhibition: Captopril Displays a Partial Selectivity for Inhibition of N-Acetyl-Seryl-Aspartyl-Lysyl-Proline Hydrolysis Compared with That of Angiotensin I, Molecular Pharmacology, 51, 10701076, 1997.

[S. A. S. Farhadi and K. F. Dizaye (2019)] S. A. S. Farhadi and K. F. Dizaye, Aliskiren, Fosinopril, and Their Outcome on Renin-Angiotensin-Aldosterone System (RAAS) in Rats with Thyroid Dysfunction, International Journal of Endocrinology, Article ID 5960563, 9 pages, 2019 doi.org/10.1155/2019/5960563

[S. Wassmann and G. Nickenig (2006)] S. Wassmann and G. Nickenig, Patophysiological regulation of the AT1 receptor and simplications for vascular disease, J. Hypertens. Suppl. 24, 15-21, 2006.

[Y. Wan et. al. (2020)] Y. Wan, J. Shang, R. Graham, R. S. Baric and F. Li, Receptor Recognition by the Novel Coronavirus from Wuhan: an Analysis Based on DecadeLong Structural Studies of SARS Coronavirus, Journal of Virology, 94, e00127-20, 2020, doi.org/10.1128/JVI.00127-20.

[D.E. Gordon, et. al.(2020)] D.E. Gordon, G.M. Jang, M. Bouhaddou, J. Xu, K. Obernier, M.J O'Meara, J.Z. Guo, et al A SARS-CoV-2-Human ProteinProtein Interaction Map Reveals Drug Targets and Potential Drug- Repurposing, doi.org/10.1101/2020.03.22.002386. 
[B.Polat et. al. (2010)] B. Polat, H. Suleyman and H. H. Alp, Adaptation of rat gastric tissue against indomethacin toxicity , Chemico-Biological Interactions, 186, 82-89, 2010.

[Y.Gao et. al. (2020)] Y. Gao, L. Yan, Y. Huang, F. Liu, Y. Zhao, L. Cao, T. Wang, Q. Sun, Z. Ming, L. Zhang et al, Structure of RNA-dependent RNA polymerase from 2019-nCoV, a major antiviral drug, biorxiv doi.org/10.1101/2020.03.16.993386.

[D. L. Boyle et. al. (2019)] D. L. Boyle, S. E. DePrimo, C. Calderon, D. Chen, P. J. Dunford, W. Barchuk, G. S. Firestein and R. L. Thurmond, Toreforant, an orally active histamine $\mathrm{H}_{4}$ - receptor antagonist, in patients with active rheumatoid arthritis despite methotrexate: mechanism of action results from a phase 2, multicenter, randomized, double-blind, placebo-controlled synovial biopsy study, Inflammation Research, 2019, doi 10.1007/s00011-019-01218-y.

[C. Ballerini et. al. (2013)] C. Ballerini, A. Aldinucci, I. Luccarini, A. Galante, C. Manuelli, P. Blandina, M. Katebe, P. L. Chazot, E. Masini and M. B. Passani, Antagonism of histamine $\mathrm{H}_{4}$ receptors exacerbates clinical and pathological signs of experimental autoimmune encephalomyelitis , British Journal of Pharmacology, 170, 67-77, 2013.

[M. Zhang et. al. (2006)] M. Zhang, R.L. Thurmond and P.J. Dunford The histamine H4 receptor: A novel modulator of inflammatory and immune disorders, Pharmacology \& Therapeutics 113, 2006, doi.org/10.1016/j.pharmthera.2006.11.008.

[C. Amici et. al. (2006)] C. Amici, A. Di Caro, A. Ciucci, L. Chiappa, C. Castilletti, V. Martella, N. Decaro, C. Buonavoglia, M. R Capobianchi and M G. Santoro, Indomethacin has a potent antiviral activity against SARS coronavirus, Antiviral Therapy 11, 10211030, 2006.

[M. Adami and G. Coruzzi (2014)] M. Adami and G. Coruzzi, The Histamine H4 Receptor: A Novel Target for Safe Anti-inflammatory Drugs? , Gastro, 1, 7-12, 2014, dx.doi.org/GOJ/GOJ-1-103.

[K. Takeshita et. al. (2003)] K. Takeshita, K. Sakai, K. B. Bacon and F. Gantner, Critical role of Histamine 4 receptor in leukotriene $B 4$ production and mast cell-dependent neutrophil recruitment induced by zymosan in vivo, J. Pharmacol. Exp. Ther. 307,10721078, 2003.

[B. Russell1 et. al. (2020)] B. Russell1, C. Moss, A. Rigg and M. Van Hemelrijck, COVID19 and treatment with NSAIDs and corticosteroids: should we be limiting their use in the clinical setting? , ecancer, 14, 1023-1026, 2020, doi.org/10.3332/ecancer.2020.1023.

[Z.I. Akhmedjanova et. al. (2012] Z.I. Akhmedjanova, M.V. Zalyalieva and R.R. Begisheva, Influence of histamine on the immunoregulation of HIV-infected patients, Int. J. of Collab. Research on Internal Med. \& Publ. Health, 4, 1084-1091, 2012.

[D. G. Ahn et. al. (2014)] D. G. Ahn, J. K. Choi, D. R. Taylor and J. W. Oh, Biochemical characterization of a recombinant $S A R S$ coronavirus nsp12 RNA-dependent $R N A$ polymerase capable of copying viral RNA templates, Arch Virol 157, 20952104, 2012.

[P. Ioannou (2020)] P. Ioannou, Non-steroidal anti-inflammatory drugs and covid-19, BMJ, letter to the editor, doi.org/10.1136/bmj.m1185, 2020.

[L. Rodriguez et. al. (2010)] L. Rodriguez, M. Noguera J. Bertran and M. Sodupe, Hydrogen bonding and proton transfer in ionized DNA base pairs, amino acids and peptides In: Quantum Biochemistry, Ed.: C.F. Matta, pp. 219-243, Wiley Publ. 2010. 
${ }_{592}$ [Han Geurdes(1987)] Han Geurdes, Master thesis quantum chemical modelling of Vaso${ }_{593} \quad$ pressine and Oxytocine, Leiden University 1987. 